\title{
Circular RNA circCDK13 suppresses cell proliferation, migration and invasion by modulating the JAK/STAT and PI3K/AKT pathways in liver cancer
}

\author{
QU LIN ${ }^{1,2^{*}}$, YUN-BIAO LING ${ }^{2,3^{*}}$, JUN-WEI CHEN ${ }^{2,4 *}$, CHU-REN ZHOU $^{2,4}$, \\ JIE CHEN $^{1,2}, \mathrm{XING} \mathrm{LI}^{1,2}$ and MING-SHENG HUANG ${ }^{2,4}$ \\ ${ }^{1}$ Department of Medical Oncology, ${ }^{2}$ Guangdong Key Laboratory of Liver Disease Research, \\ ${ }^{3}$ Department of Hepatobiliary Surgery, and ${ }^{4}$ Department of Interventional Radiology, \\ The Third Affiliated Hospital, Sun Yat-sen University, Guangzhou, Guangdong 510630, P.R. China
}

Received September 28, 2017; Accepted March 23, 2018

DOI: 10.3892/ijo.2018.4371

\begin{abstract}
Circular RNAs have recently been disclosed as potential biomarkers for human cancers. This study aimed to characterize the expression and function of a novel circular RNA, circCDK13, in liver cancer progression, as well as to elucide the underlying mechanisms. For this purpose, circCDK13 expression was quantitatively analyzed by RT-PCR in various liver cancer cell lines and human cancerous tissues. The migration, cell cycle progression, proliferation and invasion of liver cancer cells with an enhanced circCDK13 expression were evaluated by 3-(4,5-dimethylthiazol-2-yl)-5-(3-carboxymethoxyphenyl)2-(4-sulfophenyl)-2H-tetrazolium, inner salt (MTS) assay, flow cytometry and the Transwell culture system. Microarray and western blot analyses were performed to explore the underlying signaling mechanisms. The role of circCDK13 in liver cancer was finally examined by tumorigenicity assay using nude mice. The results revealed that circCDK13 expression was suppressed in various liver cancer lines and tissue samples from patients with liver cancer (hepatocellular carcinoma). The induced overexpression of circCDK13 in the liver cancer cells markedly inhibited their migration rates, altered cell cycle progression, and suppressed the cell migratory and invasive capacities. Microarray analysis also identified numerous downstream genes regulated by
\end{abstract}

Correspondence to: Dr Ming-Sheng Huang, Department of Interventional Radiology, The Third Affiliated Hospital, Sun Yat-sen University, 600 Tianhe Road, Guangzhou Guangdong 510630, P.R. China

E-mail: huangmsh@mail.sysu.edu.cn

Dr Xing Li, Department of Medical Oncology, The Third Affiliated Hospital, Sun Yat-sen University, 600 Tianhe Road, Guangzhou, Guangdong 510630, P.R. China

E-mail: lixing9@mail.sysu.edu.cn

${ }^{*}$ Co-first authorship

Key words: circCDK13, liver cancer, liver cancer, proliferation, migration, JAK/STAT, PI3K/AKT
circCDK13, particularly those in the Janus tyrosine kinase (JAK)/ signal transducer and activator of transcription (STAT) and phosphoinositide 3-kinase (PI3K)/AKT signaling pathways. The results of the tumorigenicity assay revealed that circCDK13 overexpression significantly inhibited liver cancer progression in nude mice. On the whole, the findings of this study indicate that circCDK13 is a novel circular RNA that suppresses liver cancer progression, and that these suppressive effects are possibly mediated via the JAK/STAT and PI3K/AKT signaling pathways.

\section{Introduction}

Hepatocellular carcinoma ( $\mathrm{HCC}$ ), as the most common type of liver cancer, and is still listed as one of the leading causes of cancer-related mortality worldwide, mainly due to its association with severe cirrhosis induced by alcohol, hepatitis B and hepatitis $\mathrm{C}$ infection (1). The incidence of hepatocellular carcinoma in China has been the highest over the past years, accounting for $>50 \%$ of the global incidence of hepatocellular carcinoma (2). Despite great efforts of basic and clinical investigations focusing on hepatocellular carcinoma, our knowledge of the molecular pathology of this malignant solid tumor remains limited. The diagnosis of hepatocellular carcinoma has mainly relied on a blood test and the application of several imaging modalities, such as sonography and computer tomography, and confirmation by tissue biopsy (3). Biomarkerbased accurate diagnosis and targeting therapy has become one of the major promising innovations in current medicine (4). Previous studies have characterized alpha-fetoprotein (AFP) (5), carbohydrate antigen 19-9 (CA 19-9) (6), carcinoembryonic antigen (CEA) (7) and cancer antigen 125 (CA125) (8) as diagnostic biomarkers for hepatocellular carcinoma (9), demonstrating the great prospect of biomarker application in liver cancer diagnosis and treatment. The identification of novel biomolecules closely associated with hepatocellular carcinoma initiation and progression may promote the development of novel diagnostic and therapeutic methods.

Circular RNAs (circRNAs) refer to the group of newly identified endogenous RNA molecules that can form covalently closed continuous loops $(10,11)$, which were first 
identified early in 1976 from the RNA virus (12). Previously, this particular type of circRNA structure did not raise great interest among the research community and has long been regarded as an unusable byproduct of accidental errors in posttranscriptional RNA processing $(12,13)$. Benefitting from the great progress in new sequencing technology, the function of circRNA molecules has been re-evaluated with the identification of large numbers of such molecules from various species associated with pleiotropic physiological processes (10,13-15). For instance, the revelation of the simultaneous existence of circRNAs from more than hundreds of gene transcripts by sequencing a number of normal human cells and cancerous cell lines has indicated that this particular RNA molecule structure produced by non-canonical RNA splicing may be a prevalent and important form of gene expression in human cells (16). Recent studies have indicated that circRNAs can function as miRNA sponges and RNA binding proteins (RBPs) to modulate gene expression, and can also be translated into protein or small peptides with specific functions $(10,11,13,14,17,18)$. As a critical link in the gene expression regulatory network, circRNA molecules have been shown to be involved in various pathological processes, including neurodegenerative and cardiovascular diseases, as well as in human cancers of different organs $(10,14,19)$.

circRNAs are also involved in the pathology of human liver cancers. A recent system biology study identified 127 differentially expressed circRNAs in liver cancer cells, among which the top 5 candidates were further investigated and were shown to be able to significantly distinguish malignant liver cells by forming a complex circRNA-miRNA-mRNA network associated with various signaling pathways, such as p53 and cell cycle-related cellular regulation (20). In addition, many novel circRNA molecules have recently been found to be linked to hepatitis B-related hepatocellular carcinoma and other liver cancer types, demonstrating the great potential of circRNAs as novel biomarkers for liver cancer diagnosis and candidate targets for anticancer drug development (21-25). However, considering the complexity of hepatocellular carcinoma initiation and progression, our understanding of the roles of circRNAs in liver cancer remains largely unexplored.

Cyclin-dependent kinase 13 (CDK13) functions as one of the five transcription-regulating kinases in human cells by forming the Cdk13/Cyclin K complex to regulate transcription and pre-mRNA molecule processing (26). Specifically, the overexpression of $C K D 13$ has been shown to alter pre-RNA splicing (27). Moreover, $C D K 13$ has been identified as a novel component of the perinucleolar compartment (PNC), which is a subnuclear structure found mainly in cancer cells and is closely associated with metastatic capacity (27). More importantly, a genomic analysis using a single-nucleotide polymorphism (SNP) chip revealed that the copy number of CDK13 was frequently amplified in primary hepatocellular carcinoma and was also closely associated with the onset age in patients with HCC the disease (28), suggesting a potential role for CDK13 in liver cancer pathology. Recent large-scale sequencing studies have revealed that the CDK13 transcript could form a circRNA in various human tissues and cells (29-32). However, the specific role and underlying mechanisms of action of $C D K 13$-related circRNAs in the pathology of liver cancer remain unknown.
Recently, researchers have reported that the occurrence of liver cancer is related to certain signaling pathways. These relevant signaling pathways include the Ras/Raf/Mek/Erk pathway and PI3K/Akt/mTOR pathways (33). Tang et al found out that miR-125 suppresses the PI3K/AKT pathway to inhibit migration and invasion in liver cancer (34). In addition, the JAK/STAT signaling pathway is also recognized in liver cancer as it unregulates the tumor tissues (35). Both PI3K/AKT and JAK/STAT signaling play a significant role in cell growth and proliferation $(36,37)$, which is related to the progression of liver cancers. Moreover, the PI3K and JAK/STAT signaling pathways participate in tumor occurrence, development and infiltration in various types of cancer, such as breast cancer, nasopharyngeal carcinoma and colorectal cancer (38-40). However, research on circRNAs and these two signaling pathways is limited.

In the present study, we report the functional characterization of a novel circRNA, circCDK13 (hsa_circ_0001699), transcribed from the human $C D K 13$ gene in liver cancer cells and tissues (29). The expression and regulatory function of circCDK13 in liver cancer cell cycle progression and downstream signaling pathways, as well as its in vitro tumorigenic capacity, were also investigated, providing direct evidence of the association of circCDK13 in the progression of liver cancer.

\section{Materials and methods}

Clinical tissues, cell lines, and animals. The liver cancer tissues used in this study were collected from 62 patients with hepatocellular carcinoma who were hospitalized at the Third Affiliated Hospital of Sun Yat-sen University (Guangzou, China), after obtaining written informed consent signed by each patient from February, 2015 to February, 2016 (Table I). The sample collection processes and following analysis were approved by the Ethics Committee of the Third Affiliated Hospital of Sun Yat-sen University prior to the surgery. The clinical samples were confirmed by experienced clinical pathologists before further analysis. The liver cancer cell lines, HepG2, Huh7 and SK-Hep1 were obtained from the Cell Bank of Chinese Academy of Sciences (Shanghai, China). The cell lines, MHCC97-H, MHCC97-L and SMCC7721, and the normal liver cell line, L-02, were purchased from the American Type Culture Collection (ATCC; Manassas, VA, USA). The MHCC-LM3 cells were provided by the Liver Cancer Institute of Zhongshan Hospital, Fudan University (Shanghai, China). The liver cancer cells were cultured in DMEM supplemented with $0.1 \%$ fetal bovine serum (FBS) at $37^{\circ} \mathrm{C}$ with $5 \% \mathrm{CO}_{2}$. For the tumorigenesis assay, we used $12 \mathrm{BALB} / \mathrm{c}$ nude mice (4 weeks old, female, weighing 14-16 g) obtained from the Shanghai Laboratory Animal Center, Chinese Academy of Sciences (Shanghai, China). The mouse were housed in a controlled environment (temperature, $20-26^{\circ} \mathrm{C}$; humidity, $40-70 \% ; 12-\mathrm{h}$ light/dark cycle). The mouse experiments in this study was performed under the Affidavit of the Approval of Animal Ethical and Welfare of the Laboratory Animal Center of the Third Affiliated Hospital of Sun Yat-sen University.

RNA extraction, Sanger sequencing and reverse transcriptionquantitavie PCR (RT-qPCR). Total RNA samples from the hepatocellular carcinoma tissues and the cell lines were extracted 
Table I. Summary of the patient characteristics.

\begin{tabular}{|c|c|c|c|c|c|c|}
\hline Case & Sex & $\begin{array}{c}\text { Age } \\
\text { (years) }\end{array}$ & Diagnosis & Grade & $\begin{array}{l}\text { Tumor } \\
\text { number }\end{array}$ & $\begin{array}{c}\text { Tumor } \\
\text { size }\end{array}$ \\
\hline 1 & $\mathrm{M}$ & 58 & $\mathrm{HCC}$ & II & 1 & $>3 \mathrm{~cm}$ \\
\hline 2 & $\mathbf{M}$ & 53 & $\mathrm{HCC}$ & II & $>1$ & $>3 \mathrm{~cm}$ \\
\hline 3 & $\mathrm{M}$ & 34 & $\mathrm{HCC}$ & III & $>1$ & $>3 \mathrm{~cm}$ \\
\hline 4 & $\mathrm{M}$ & 53 & $\mathrm{HCC}$ & II & $>1$ & $>3 \mathrm{~cm}$ \\
\hline 5 & $\mathrm{~F}$ & 70 & $\mathrm{HCC}$ & II & 1 & $>3 \mathrm{~cm}$ \\
\hline 6 & $\mathrm{M}$ & 40 & $\mathrm{HCC}$ & II & $>1$ & $>3 \mathrm{~cm}$ \\
\hline 7 & $\mathrm{M}$ & 54 & $\mathrm{HCC}$ & II & $>1$ & $>3 \mathrm{~cm}$ \\
\hline 8 & M & 42 & $\mathrm{HCC}$ & II-III & 1 & $>3 \mathrm{~cm}$ \\
\hline 9 & $\mathrm{M}$ & 43 & $\mathrm{HCC}$ & II & 1 & $>3 \mathrm{~cm}$ \\
\hline 10 & $\mathrm{M}$ & 28 & $\mathrm{HCC}$ & II & 1 & $>3 \mathrm{~cm}$ \\
\hline 11 & $\mathrm{M}$ & 68 & $\mathrm{HCC}$ & II & 1 & $>3 \mathrm{~cm}$ \\
\hline 12 & $\mathrm{~F}$ & 53 & $\mathrm{HCC}$ & II & 1 & $>3 \mathrm{~cm}$ \\
\hline 13 & $\mathrm{~F}$ & 28 & $\mathrm{HCC}$ & II & $>1$ & $>3 \mathrm{~cm}$ \\
\hline 14 & $\mathrm{M}$ & 62 & $\mathrm{HCC}$ & II & 1 & $>3 \mathrm{~cm}$ \\
\hline 15 & M & 28 & $\mathrm{HCC}$ & II & $>1$ & $>3 \mathrm{~cm}$ \\
\hline 16 & $\mathrm{M}$ & 43 & $\mathrm{HCC}$ & II-III & $>1$ & $>3 \mathrm{~cm}$ \\
\hline 17 & $\mathrm{M}$ & 75 & $\mathrm{HCC}$ & II & 1 & $>3 \mathrm{~cm}$ \\
\hline 18 & $\mathrm{M}$ & 35 & $\mathrm{HCC}$ & I & 1 & $>3 \mathrm{~cm}$ \\
\hline 19 & $\mathbf{M}$ & 32 & $\mathrm{HCC}$ & II & 1 & $>3 \mathrm{~cm}$ \\
\hline 20 & $\mathrm{M}$ & 41 & $\mathrm{HCC}$ & III & 1 & $>3 \mathrm{~cm}$ \\
\hline 21 & $\mathrm{M}$ & 42 & $\mathrm{HCC}$ & II & 1 & $>3 \mathrm{~cm}$ \\
\hline 22 & $\mathrm{M}$ & 66 & $\mathrm{HCC}$ & II & $>1$ & $>3 \mathrm{~cm}$ \\
\hline 23 & $\mathrm{M}$ & 54 & $\mathrm{HCC}$ & II & 1 & $\leq 3 \mathrm{~cm}$ \\
\hline 24 & $\mathrm{M}$ & 64 & $\mathrm{HCC}$ & II & $>1$ & $>3 \mathrm{~cm}$ \\
\hline 25 & $\mathrm{M}$ & 62 & $\mathrm{HCC}$ & I & $>1$ & $>3 \mathrm{~cm}$ \\
\hline 26 & $\mathrm{M}$ & 43 & $\mathrm{HCC}$ & II & 1 & $>3 \mathrm{~cm}$ \\
\hline 27 & $\mathrm{M}$ & 59 & $\mathrm{HCC}$ & II & $>1$ & $>3 \mathrm{~cm}$ \\
\hline 28 & $\mathrm{M}$ & 61 & HCC & II & $>1$ & $>3 \mathrm{~cm}$ \\
\hline 29 & $\mathrm{M}$ & 36 & $\mathrm{HCC}$ & III & 1 & $>3 \mathrm{~cm}$ \\
\hline 30 & M & 34 & $\mathrm{HCC}$ & II & 1 & $>3 \mathrm{~cm}$ \\
\hline 31 & M & 34 & $\mathrm{HCC}$ & II & $>1$ & $>3 \mathrm{~cm}$ \\
\hline 32 & M & 57 & $\mathrm{HCC}$ & III & 1 & $>3 \mathrm{~cm}$ \\
\hline 33 & $\mathrm{M}$ & 76 & $\mathrm{HCC}$ & III & 1 & $>3 \mathrm{~cm}$ \\
\hline 34 & $\mathrm{M}$ & 72 & $\mathrm{HCC}$ & I & $>1$ & $>3 \mathrm{~cm}$ \\
\hline 35 & $\mathrm{~F}$ & 46 & $\mathrm{HCC}$ & II & $>1$ & $>3 \mathrm{~cm}$ \\
\hline 36 & $\mathrm{M}$ & 64 & $\mathrm{HCC}$ & III & 1 & $>3 \mathrm{~cm}$ \\
\hline 37 & $\mathrm{M}$ & 29 & $\mathrm{HCC}$ & II & 1 & $>3 \mathrm{~cm}$ \\
\hline 38 & M & 50 & HCC & II & 1 & $\leq 3 \mathrm{~cm}$ \\
\hline 39 & $\mathrm{M}$ & 52 & $\mathrm{HCC}$ & III & 1 & $>3 \mathrm{~cm}$ \\
\hline 40 & $\mathrm{M}$ & 43 & $\mathrm{HCC}$ & II & 1 & $>3 \mathrm{~cm}$ \\
\hline 41 & $\mathrm{~F}$ & 67 & $\mathrm{HCC}$ & III & $>1$ & $>3 \mathrm{~cm}$ \\
\hline 42 & $\mathrm{M}$ & 47 & $\mathrm{HCC}$ & II & 1 & $\leq 3 \mathrm{~cm}$ \\
\hline 43 & M & 31 & $\mathrm{HCC}$ & II & 1 & $>3 \mathrm{~cm}$ \\
\hline 44 & M & 66 & $\mathrm{HCC}$ & I & $>1$ & $>3 \mathrm{~cm}$ \\
\hline 45 & $\mathrm{M}$ & 54 & $\mathrm{HCC}$ & II & $>1$ & $\leq 3 \mathrm{~cm}$ \\
\hline 46 & $\mathrm{M}$ & 42 & $\mathrm{HCC}$ & II & $>1$ & $>3 \mathrm{~cm}$ \\
\hline 47 & $\mathrm{M}$ & 59 & $\mathrm{HCC}$ & II & 1 & $>3 \mathrm{~cm}$ \\
\hline 48 & M & 65 & HCC & I & 1 & $>3 \mathrm{~cm}$ \\
\hline 49 & M & 45 & HCC & III & $>1$ & $\leq 3 \mathrm{~cm}$ \\
\hline 50 & $\mathrm{M}$ & 58 & $\mathrm{HCC}$ & I & 1 & $>3 \mathrm{~cm}$ \\
\hline 51 & M & 53 & $\mathrm{HCC}$ & II & $>1$ & $>3 \mathrm{~cm}$ \\
\hline 52 & M & 53 & $\mathrm{HCC}$ & II & $>1$ & $>3 \mathrm{~cm}$ \\
\hline 53 & $\mathrm{M}$ & 68 & $\mathrm{HCC}$ & II & 1 & $>3 \mathrm{~cm}$ \\
\hline 54 & $\mathrm{M}$ & 35 & $\mathrm{HCC}$ & I & 1 & $>3 \mathrm{~cm}$ \\
\hline 55 & $\mathrm{M}$ & 43 & $\mathrm{HCC}$ & II & 1 & $>3 \mathrm{~cm}$ \\
\hline 56 & $\mathrm{M}$ & 71 & $\mathrm{HCC}$ & III & 1 & $>3 \mathrm{~cm}$ \\
\hline 57 & $\mathrm{M}$ & 38 & $\mathrm{HCC}$ & II & $>1$ & $\leq 3 \mathrm{~cm}$ \\
\hline 58 & $\mathrm{M}$ & 61 & HCC & III & 1 & $>3 \mathrm{~cm}$ \\
\hline 59 & $\mathrm{M}$ & 58 & $\mathrm{HCC}$ & II & 1 & $\leq 3 \mathrm{~cm}$ \\
\hline 60 & $\mathrm{~F}$ & 41 & $\mathrm{HCC}$ & III & $>1$ & $>3 \mathrm{~cm}$ \\
\hline 61 & $\mathrm{M}$ & 51 & $\mathrm{HCC}$ & II & $>1$ & $>3 \mathrm{~cm}$ \\
\hline 62 & $\mathrm{M}$ & 62 & $\mathrm{HCC}$ & II & $>1$ & $>3 \mathrm{~cm}$ \\
\hline
\end{tabular}

M, male; F, female; HCC, hepatocellular carcinoma. using the PureLink ${ }^{\mathrm{TM}}$ RNA Mini kit (cat. no. 12183018A; Thermo Fisher Scientific, Inc., Waltham, MA, USA) following the manufacturer's instructions. The tissues were fully homogenized in liquid nitrogen, and the fine powder was used for RNA extraction. The synthesis of cDNA with $\sim 2 \mu \mathrm{g}$ of total RNA was completed using the High-Capacity cDNA Reverse Transcription kit (cat. no. 4368813; Thermo Fisher Scientific, Inc.) according to the manufacturer's instructions. Quantitative (real-time) polymerase chain reaction (qPCR) was carried out to determine the relative gene transcript or circular RNA levels using the SYBR Select Master Mix kit (cat. no. 4472908; Applied Biosystems, Foster City, CA, USA) following the manufacturer's instructions. For the quantification of circNA levels, divergent primers were designed, and oppositedirected pairs of primers were used to assess the gene transcript level. The GAPDH gene was used as the internal control. Each quantitative analysis was performed at least 3 times for statistical analysis. For the identification of the ligation site of circCDK13, the PCR products were analyzed by Sanger sequencing. Briefly, the purified double-stranded CDNA was repaired at the end and added poly-A ends and then ligated. The PCR method was then used for the amplification of the cDNA. The library of cDNA was then detected using Agilent 2100 system software and quantified by qPCR. The library was then sequenced using the illumina Hiseq 2000 platform (Illumina, San Diego, CA, USA). The sequences of the primers used in this study were as follows: $C D K 13$ exon 5 forward, 5'-AGATGCTTT GGATTTCAAGAAGG-3'; $C D K 13$ exon 2 reverse, 5'-TGACGA CTTCTGGATCTAGACAATC-3'; CDK13 exon 6 forward, 5'-CCACTTACACCAAGCATAGGA-3'; CDK13 exon 9 reverse, 5'-CTTCTTTATCTTCAGGCAGCAT-3'; and GAPDH forward, 5'-GAGTCAACGGATTTGGTCGT-3'; and reverse, 5'-GAC AAGCTTCCCGTTCTCAG-3'.

Plasmid construction and cell transfection. The establishment of liver cancer cells overexpressing circRNA was conducted according to the protocols described in a previous study (41). Briefly, the cDNA of circCDK13 was synthesized by the Nuclee Biotechnology Company (Guangzhou, China) and cloned into the lentiviral expression vector, pLVX-IRESneo (Clontech Laboratories Inc., San Francisco, CA, USA; pLVX-IRESneo was used as the control vector). The cDNA sequence encoding exons 2-5 of the $C D K 13$ gene, together with the additional sequence $500 \mathrm{bp}$ upstream and $300 \mathrm{bp}$ downstream of the non-linear splice site, were used in this study. Following construction, direct sequencing was performed to verify the sequences. Subsequently, the construct was used to transfect the liver cancer cells with Lipofectamine 2000 reagent (Invitrogen, Carlsbad, CA, USA). The expression of circular RNA in transfected cells was confirmed by RT-qPCR using specific primers pairs. At $24 \mathrm{~h}$ following transfection, the following experiments were carried out.

MTS assay. The proliferative potential of the liver cancer cells was determined using the (3-(4,5-dimethylthiazol-2-yl)5-(3-carboxymethoxyphenyl)-2-(4-sulfophenyl)-2H-tetrazolium, inner salt) (MTS) assay using the MTS Assay (Cell Proliferation) (Colorimetric) kit (cat. no. ab197010; Abcam, Cambridge, UK) according to the manufacturer's instructions. Briefly, the cells transfected with lentiviral expression vectors were counted under 
a microscope, and $100 \mu \mathrm{l}$ cell suspension was seeded into each well of a 96-well plate $\left(1 \times 10^{4}\right.$ cells/well) and cultured at $37^{\circ} \mathrm{C}$ with a suitable level of $\mathrm{CO}_{2}$. Following adherence, $10 \mu \mathrm{l}$ MTS solution were added at 24,48 and $72 \mathrm{~h}$. The absorbance at $490 \mathrm{~nm}$ (OD490) was measured using a spectrophotometer (ELx800; BioTek Instruments, Inc., Winooski, VT, USA) following culture at $37^{\circ} \mathrm{C}$ for $4 \mathrm{~h}$. At least 3 biological and technical replicates were analyzed.

Cell cycle assay. The effects of the circRNA on cell cycle progression were evaluated by measuring the percentages of cells in the G0/G1, M and G2 phases of the cell cycle using the Cell Cycle kit (cat. no. F559763; Forevergen, Guangzhou, China) following the manufacturer's instructions. Briefly, the liver cancer cells were washed 3 times with PBS solution, suspended by digestion with trypsin, and washed and collected by centrifugation at $300 \mathrm{x} \mathrm{g}$ for $1 \mathrm{~min}$. After cell counting, $1 \times 10^{6}$ cells were fixed with $70 \%$ ice ethanol at $-20^{\circ} \mathrm{C}$ overnight, collected by centrifugation at $500 \mathrm{x} \mathrm{g}$ for $5 \mathrm{~min}$, and then washed twice with PBS solution. The cell pellets were mixed and resuspended in $500 \mu \mathrm{l}$ cell cycle staining solution, cultured at $37^{\circ} \mathrm{C}$ for $30 \mathrm{~min}$, and finally detected by flow cytometry (FACSCalibur flow cytometer; BD Biosciences, San Jose, CA, USA). To evaluate statistical significance, at least 3 biological and technical replicates were performed for this assay.

Cell migration assay. The Transwell culture system was used to determine the effects of the circRNA overexpression on the liver cancer cell migratory capacity. The cultured liver cancer cells transfected with the expression plasmids were digested into a single-cell suspension with trypsin and counted under a microscope (IM-35; Carl Zeiss Inc., Thornwood, NY, USA). The cell density was adjusted to $1 \times 10^{6} / \mathrm{ml}$ using serum-free medium. The upper chambers were filled with a $100 \mu \mathrm{l}$ cell suspension, and the lower chambers were filled with complete medium containing $10 \%$ FBS. The cells were then cultured at $37^{\circ} \mathrm{C}$ for $24 \mathrm{~h}$ in a humidified atmosphere with $5 \% \mathrm{CO}_{2}$. The cells in the lower chambers were then fixed with $4 \%$ paraformaldehyde for $10 \mathrm{~min}$, washed once with PBS solution, stained with crystal violet for $10 \mathrm{~min}$, washed again with PBS solution, and finally counted and photographed with a Leica DC300F digital microscope (Leica Camera AG, Solms, Germany). Three biological replicates were performed for the statistical analysis of the cell proliferative capacity.

Cell invasion assay. The invasion capacity of the liver cancer cells was also measured using the Transwell culture system. Specifically, a layer of Matrigel Basement Membrane Matrix (BD Biocoat; BD Biosciences, Bedford, MA, USA) was laid on the inner sides of the Transwell chambers according to the manufacturer's instructions, to mimic the in vivo extracellular matrix environment. The liver cancer cells were suspended by trypsin digestion, and the cell density was determined by counting under a microscope and diluted to $1 \times 10^{6} / \mathrm{ml}$. The upper and lower chambers were filled with a $100 \mu \mathrm{l}$ cell suspension and $600 \mu \mathrm{l}$ culture medium, respectively, and then maintained at $37^{\circ} \mathrm{C}$ for $24 \mathrm{~h}$. The cancer cells in the lower chambers were then fixed with $4 \%$ paraformaldehyde for $15 \mathrm{~min}$, washed once with PBS solution, stained with $1 \%$ crystal violet solution for 10 min, washed again with PBS solution, and finally counted and photographed. Three biological replicates were evaluated for statistical analysis.

Microarray analysis. The expression patterns of the liver cancer cells overexpressing circCDK13 were analyzed by microarray assay as previously described (42). Briefly, total RNA samples were extracted from the liver cancer cells using the PicoPure ${ }^{\mathrm{TM}}$ RNA Isolation kit (cat. no. KIT0204; Applied Biosystems) following the manufacturer's instructions. cDNA synthesis was carried out using the Agilent in situ Hybridization Kit plus (Agilent Technologies, Wilmington, DE, USA). The complementary double-stranded cDNA labeled with $\mathrm{Cy} 3$ or $\mathrm{Cy} 5$ was then hybridized and subjected to microarray analysis using Agilent Human G4131F 4x44 K. The spot intensities were then determined and analyzed using ImaGene 8.0 software and Nexus Expression software (BioDiscovery, El Segundo, CA, USA). Gene spots showing differences exceeding 1.5-fold were defined as differentially expressed genes and selected for subsequent clustering analysis. The heatmap and enrichment analysis of the signaling pathways were completed by searching against the Koyto Encyclopedia of Genes and Genomes (KEGG) database (www.genome.jp/kegg/pathway.html).

Western blot analysis. The abundances of several major signaling components were measured by western blot analysis as previously described (42). After the cells were washed with PBS solution, total proteins were lysed in RIPA buffer $(50 \mathrm{mM}$ Tris $\mathrm{HCl}$, pH 7.4; $150 \mathrm{mM} \mathrm{NaCl} ; 1 \%$ NP-40; $0.5 \%$ sodium deoxycholate), extracted from the liver cancer cells and boiled with sample loading buffer at $100^{\circ} \mathrm{C}$ for $5 \mathrm{~min}$. BCA assay was used to quantify the total protein. Approximately $30 \mathrm{mg}$ proteins was loaded and separated by $12 \%$ SDS-PAGE, transferred onto PVDF membranes, and incubated with 5\% lipid-free milk solution, primary antibodies and secondary antibodies. The blots were finally developed with ECL solution $\left(\right.$ Amersham $^{\mathrm{TM}}$ ) and exposed to film. The primary antibodies used in this study included anti-AKT1/2/3 (cat. no. ab106693), anti-AKT (phospho; cat. no. ab106693), anti-STAT3 (cat. no. ab68153), anti-STAT3 (phospho Y705) (cat. no. ab76315) and anti-GAPDH (cat. no. ab8245) antibodies, which were purchased from Abcam. The secondary antibody horseradish peroxidase-conjugated goat antimouse or anti-rabbit secondary antibodies (cat. no. 115-035-044) were purchased from Jackson ImmunoResearch (West Grove, PA, USA). For statistical quantification, 3 biological repeats were performed, and GAPDH was used as the internal standard.

Tumorigenicity assay. The liver cancer cells in logarithmic growth phase were collected by washing with PBS solution and digestion with trypsin, and resuspended in PBS solution. The cell density was adjusted to $5 \times 10^{7} / \mathrm{ml}$. Nude mice were subcutaneously injected with $100 \mu$ l Sk-hep-1 NC or Sk-hep-1 circCDK13 cell suspension (6 mice in each group) into the left armpit. The tumor volumes were calculated each week using the following formula: Tumor volume $\left(\mathrm{mm}^{3}\right)=$ tumor length $\mathrm{x}$ tumor width $\mathrm{x}$ tumor width/2. The tumors were finally weighed and photographed 45 days later.

Statistical analysis. Significant differences between multiple groups were analyzed by the one-way ANOVA with the Least 
A

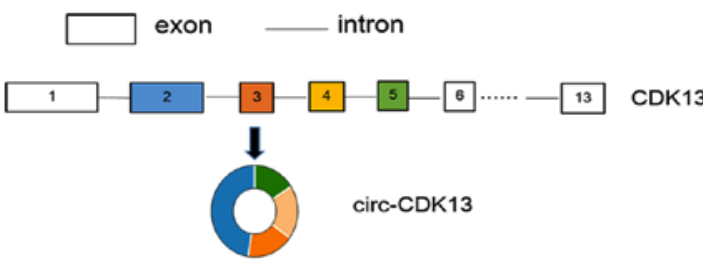

B

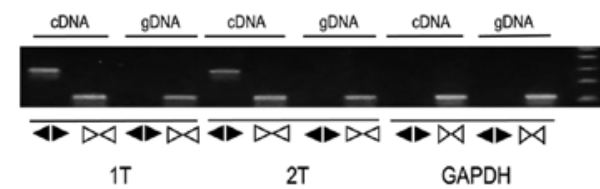

C

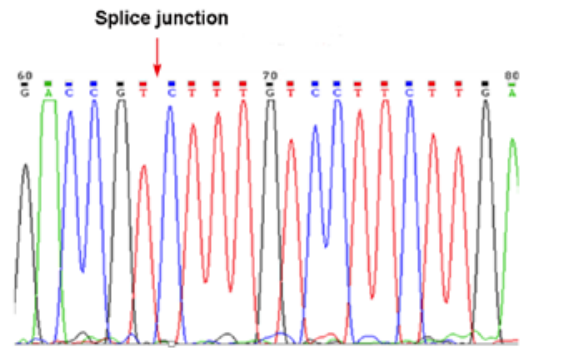

D

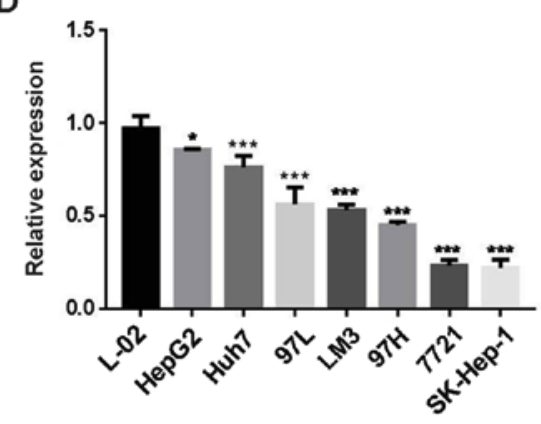

E

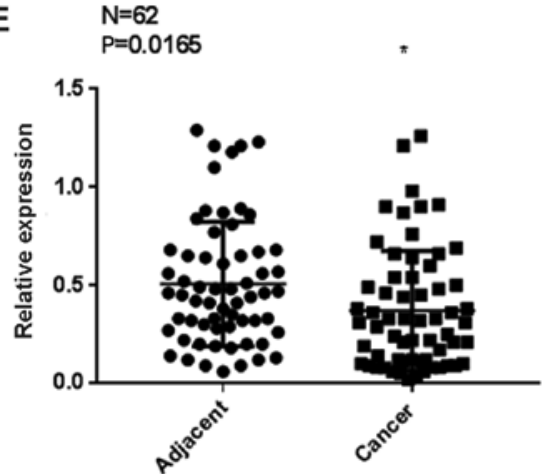

Figure 1. Expression of circCDK13 in liver cancer. (A) Schematic of circCDK13 formation. (B) Detection of circCDK13 in hepatocellular carcinoma tissues. RT-qPCR using primers targeting the genomic or circular RNA was performed. GAPDH was used as the negative control. (C) The ligation site of circCDK13. Sanger sequencing was used to confirm the circular form and ligation site of circCDK13 in cancerous tissues. (D) Expression levels of circCDK13 in liver cancer cell lines. The expression levels of circCDK13 among 7 liver cancer cell lines and normal human liver cells (L-02) were detected by RT-qPCR. ${ }^{*} \mathrm{P}<0.05$, HepG2 vs. L-02 cells; ${ }^{* * *}$ P<0.001, Huh7, MHCC97-L (97L), MHCC-LM3 (LM3), MHCC97-H (97H), SMCC7721 (7721), SK-Hep-1 vs. L-02 cells. (E) Expression levels of circCDK13 in hepatocellular carcinoma tissues. The expression levels of circCDK13 in human cancerous liver tissues were detected by RT-qPCR. ${ }^{*} \mathrm{P}<0.05$, cancer tissues vs. adjacent tissues.

Significant Difference (LSD) test, and differences between 2 groups were analyzed by the Student's t-test using the SPSS 18.0 software package. A significant difference was defined by a P-value $<0.05$.

\section{Results}

circCDK13 expression is decreased in liver cancer. By bioinformatics searches against the circBase database (29) and several large-scale investigations using deep sequencing (30-32), the circRNA circCDK13 was produced from 4 exons encoded by $C D K 13$, as shown in Fig. $1 \mathrm{~A}$. The ligation of the second and fifth exons of the $C D K 13$ transcript formed the circular structure of circCDK13 (Fig. 1A). For the investigation of the circCDK13 in the context of liver cancer, the expression of circCDK13 in the cancer tissues from 2 patients with hepatocellular carcinoma was examined by RT-qPCR with 2 different primer pairs targeting the genomic DNA and circRNA, respectively. Our results revealed the circular form of $C D K 13$ RNA, circCDK13, in the clinical samples from these 2 patients with hepatocellular carcinoma (Fig. 1B). The ligation site of circCDK13 was identified by Sanger sequencing of the PCR products, further confirming the presence of the circular from of circCDK13 (Fig. 1C). Subsequently, we measured the expression levels of circCDK13 in 7 liver cancer cell lines, and found that the circCDK13 levels in these cancerous cells were all significantly lower than those in the control L-02 cells, supporting the potential involvement of $\operatorname{circCDK} 13$ in liver cancer progression (Fig. 1D). The decrease in $\operatorname{circCDK13}$ expression was also observed in a large number of patients with hepatocellular carcinoma by RT-qPCR (Fig. 1E). The observed expression levels of circCDK13 in both liver cancer tissues and cell lines suggested that circCDK13 might play regulatory roles during the initiation and development of hepatocellular carcinoma.

Overexpression of circCDK13 suppresses cancer cell proliferation and cell cycle progression. To investigate the possible roles of circCDK13 during liver cancer development, we established SK-Hep-1 and Huh7 cells overexpressing circCDK13 using the lentiviral expression system as described in the Materials and methods. According to the results shown in Fig. 1D, the expression of circCDK13 differed significantly between the different cell lines. The expression of circCDK13 in the HepG2 and Huh7 cells was higher than that in the other cells, while the expression of circCDK13 was lowest in the SK-Hep-1 cells. Thus, the HepG2, Huh7 and SK-Hep-1 were the candidate cells. However, after screening, we found that the invasive ability of the HepG2 cells was weak, and these cells were thus not suitable for following experiments. Hence, the Huh7 and SK-Hep-1 cells were selected for use in further experiments. By RT-qPCR analysis, we observed that the expression levels of circCDK13 in the SK-Hep1 and Huh7 cells were markedly elevated following transfection with the overexpression plasmid compared with the negative control (Fig. 2A). Moreover, the proliferation rates of both the SK-Hep1 and 

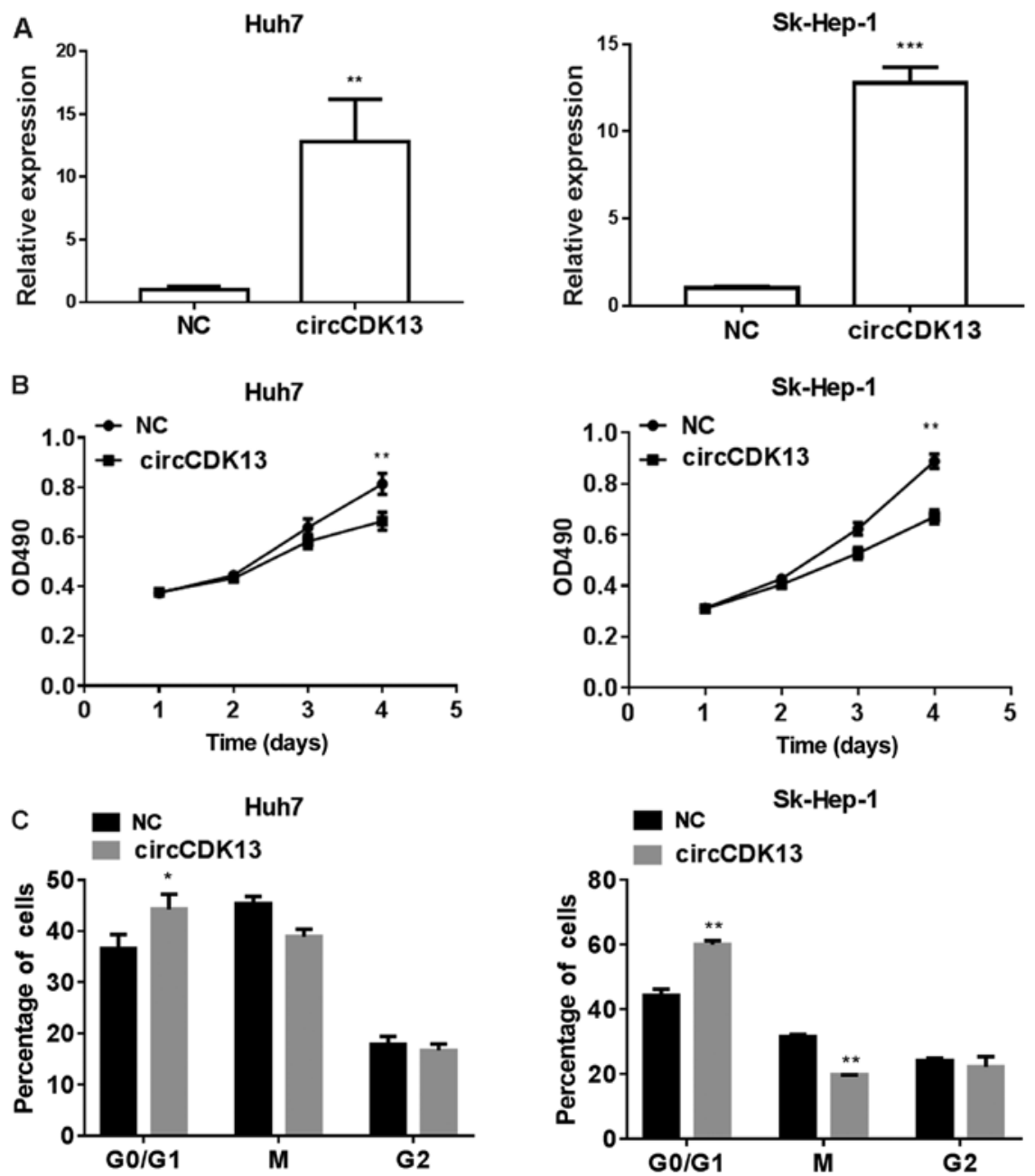

Figure 2. Inhibition of liver cancer cell proliferation and cell cycle progression by overexpression of circCDK13. (A) Expression levels of circCDK13 in liver cancer cells following transfection with circCDK13 overexpression plasmid or negative control. RT-qPCR was performed to measure the circCDK13 expression level. (B) Proliferation rates of liver cancer cells with an elevated circCDK13 expression induced by transfection with circCDK13 overexpression plasmid. The proliferation rates of the liver cancer cells were examined by MTS assay. (C) Cell cycle progression of the liver cancer cells with an elevated circCDK13 expression induced by transfection with circCDK13 overexpression plasmid. The percentages of liver cancer cells in the different phases of the cell cycle were determined by flow cytometry. NC, negative control; circCDK13, circular CDK13 overexpression plasmid. " $\mathrm{P}<0.05$, circCDK13 vs. NC; ${ }^{* *} \mathrm{P}<0.01$, circCDK13 vs. $\mathrm{NC} ;{ }^{* * *} \mathrm{P}<0.001$, circCDK13 vs. $\mathrm{NC}$.

Huh7 cells overexpressing circCDK13 were significantly lower than those of the control group (Fig. 2B), indicating the role of circCDK13 in regulating liver cancer cell proliferation during liver cancer development. Additionally, the percentages of liver cancer cells in the G0/G1, M and G2 phases of the cell cycle were analyzed by flow cytometry, and we observed that a greater number of circCDK13-overexpressing liver cancer cells compared with the negative controls were in the G0/G1 phase of the cell cycle, while the number of cells in the $\mathrm{M}$ phase was decreased by circCDK13 overexpression (Fig. 2C). These results indicated that the expression of circCDK13 played an important role in the pathology of liver cancer by modulating cell proliferation and cell cycle progression.

circCDK13 inhibits liver cancer cell migration and invasion. The dysregulation of cell migration and aberrant cell invasion are characteristics of liver cancer. For the further verification of the role of circCDK13 in the pathological processes of liver cancer, the migratory and invasive capacity of the SK-Hep-1 and Huh7 cells overexpressing circCDK13 were evaluated in this study. As shown in Fig. 3A, the results of Transwell culture assay revealed that the increase in circCDK13 expression markedly suppressed the migratory rates of both the SK-Hep1 and Huh7 cells compared with those of the control group (Fig. 3A). Similar to the migration assay, we found that the invasive capacity of the SK-Hep-1 and Huh7 cells overexpressing circCDK13 was also significantly suppressed compared with the control group (Fig. 3B). In both the migration and invasion assays, the Sk-Hep-1 cells overexpressing circCDK13 exhibited a highly significant decrease in cell numbers compared with the control group (Fig. 3). The markedly suppressed migratory and invasive abilities of the human liver cancer cells directly confirmed that this newly identified circRNA molecule is as an essential factor for liver cancer development as it suppresses cell migration and invasion, as well as cell proliferation and cell cycle progression.

circCDK13 overexpression regulates JAK/STAT and PI3K/ $A K T$ signaling. To investigate the molecular mechanisms underlying the effects of circCDK13 on liver cancer cell 
A

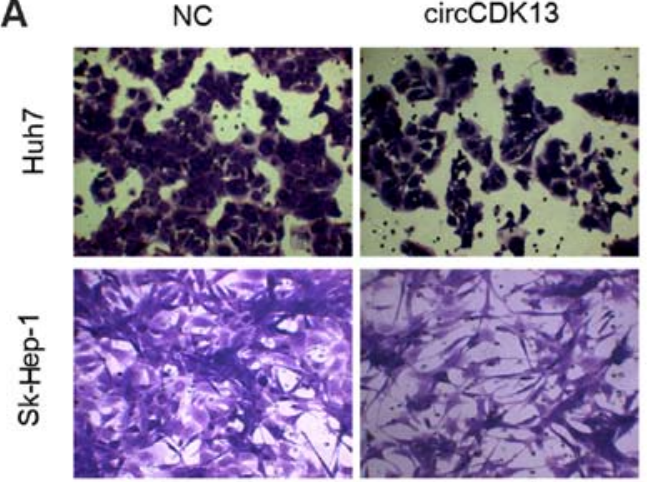

B

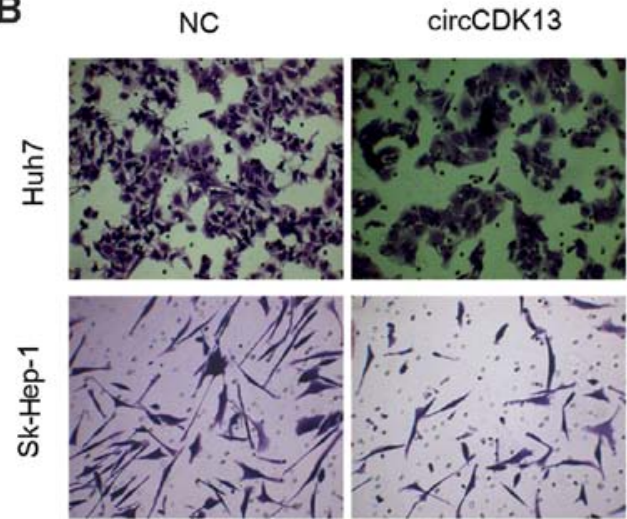

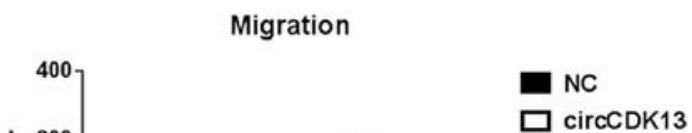

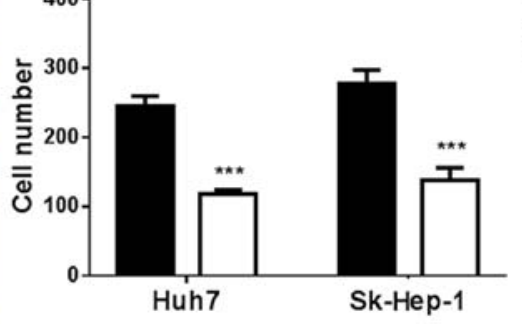

Invasion

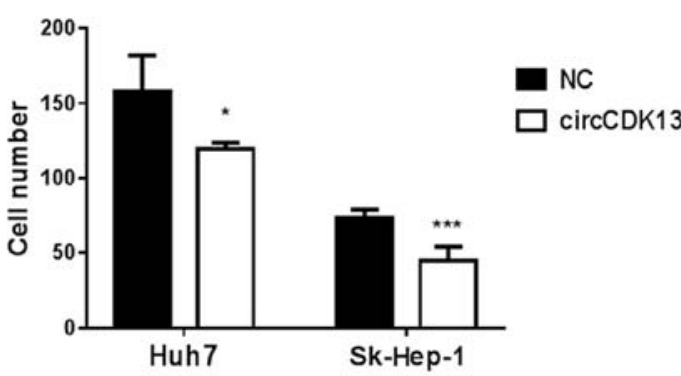

Figure 3. Suppression of liver cancer cell migration and invasion by circCDK13. (A) The migratory capacity of the liver cancer cells overexpressing circCDK13 by transfection with circCDK13 overexpression plasmid was assessed by Transwell assay. The cell migratory potentials were analyzed using the Transwell culture system and crystal violet staining. (B) The invasive ability of the human liver cancer cells overexpressing circCDK13 by transfection with circCDK13 overexpression plasmid. Cell invasion was assessed using the Transwell system and staining with crystal violet. NC, negative control; circCDK13, circular CDK13 overexpression plasmid. ${ }^{*} \mathrm{P}<0.05$, circCDK13 vs. $\mathrm{NC} ;{ }^{* * * *} \mathrm{P}<0.001$, circCDK13 vs. $\mathrm{NC}$.

proliferation, migration and invasion, transcriptome analysis using a microarray assay was performed to compare the differences in expressional profiles between the liver cancer cells overexpressing circCDK13 and the control group. In total, $>4,000$ genes were found to be significantly differentially expressed in the liver cancer cells overexpressing circCDK13 compared with the negative control, including 3,513 upregulated and 1,671 downregulated genes (Fig. 4A). Moreover, our KEGG pathway analysis revealed that these differentially expressed genes were significantly enriched in the JAK/STAT, PI3K/AKT and focal adhesion signaling pathways (Fig. 4B). Specifically, transcriptome analysis revealed that several genes in the JAK/STAT and PI3K/AKT pathways were differentially expressed in the liver cancer cells with an enhanced circCDK13 expression (Fig. 5A). The results from transcriptome and bioinformatics analysis strongly indicated that the functions of circCDK13 in regulating liver cancer cell proliferation, migration and invasion were mediated by multiple signaling pathways. Furthermore, the levels of phosphorylated AKT (p-AKT) and phosphorylated STAT3 (p-STAT3) proteins were markedly downregulated in both the Huh7 and SK-Hep-1 cells overexpressing circCDK13, directly confirming that the JAK/STAT and PI3K/AKT pathways were regulated by circCDK13 in liver cancer cells (Fig. 5B). These results revealed that circCDK13 regulates various signaling pathways in the liver cancer pathological processes, and JAK/STAT and PI3K/AKT may be two of the major mediating signaling pathways.
circCDK13 suppresses the tumorigenicity of liver cancer cells. For further confirmation of the role of circCDK13 in liver cancer progression, a tumorigenicity assay was carried out by transplanting Sk-Hep-1 cells overexpressing circCDK13 or negative control cells into nude mice. The tumors formed from the liver cancer cells overexpressing circCDK13 were much smaller than those derived from the negative control group (Fig. 6A). Consistently, the tumor volumes in the experimental groups with an elevated circCDK13 expression were also significantly smaller compared with those in the negative control (Fig. 6B). Additionally, markedly decreased tumor weights were observed in the experimental group of mice transplanted with liver cancer cells overexpressing circCDK13 (Fig. 6C). The significantly suppressed tumor-forming capacity of the liver cancer cells overexpressing circCDK13 strongly supports our hypothesis that circCDK13 functions as a novel circRNA molecule associated with liver cancer cell proliferation and migration during liver cancer development and progression.

\section{Discussion}

The re-discovery of circRNAs as revalently expressed macromolecules with significant physiological and pathological importance has opened a new and broad research field for the study of malignant diseases. In light of progress being made in research in recent years, it has become widely accepted that circRNAs may be explored as biomarkers for various 
A
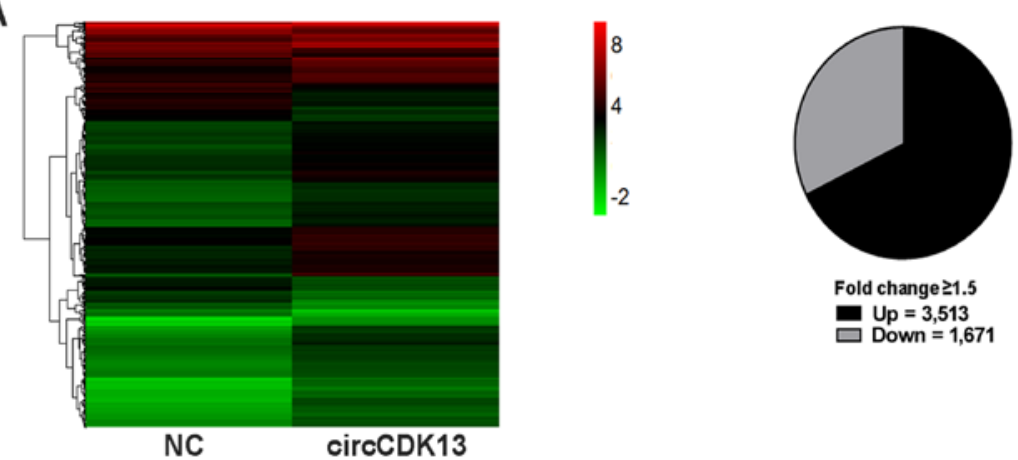

B

Top20 od pathway enrichment

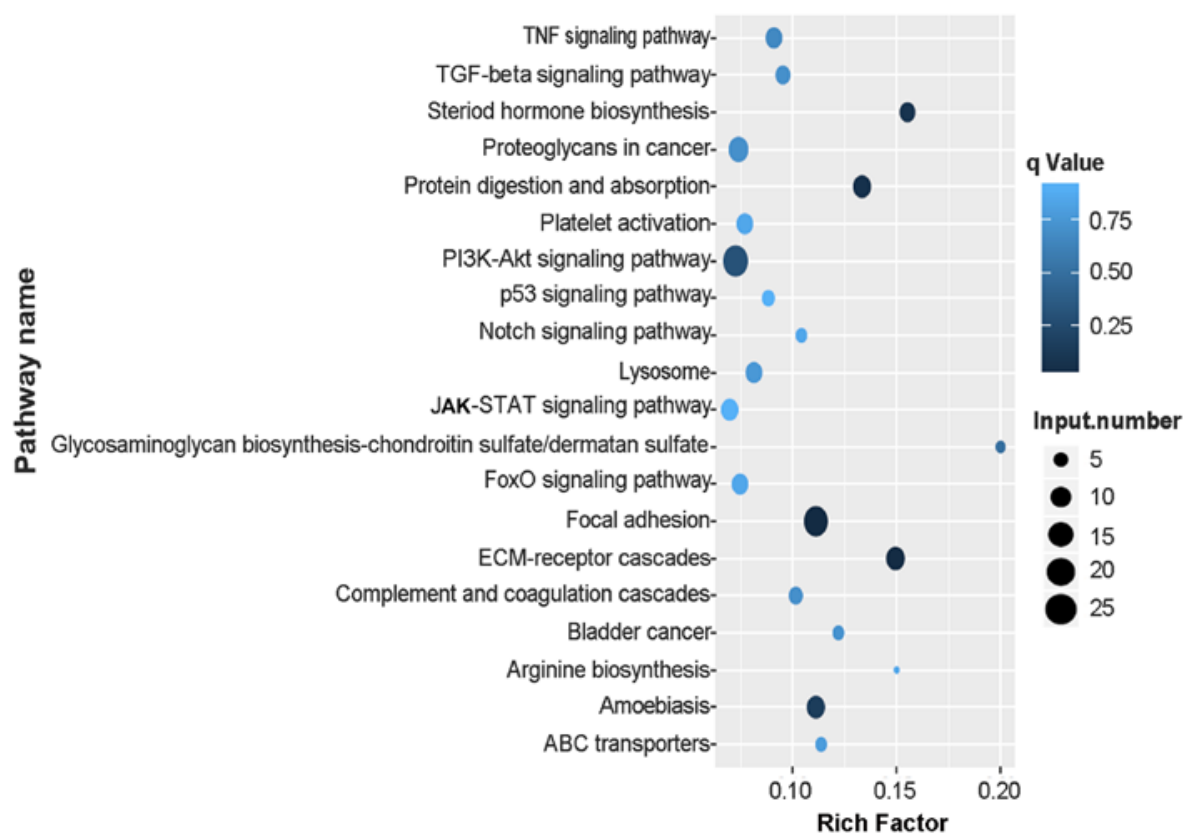

Figure 4. Transcriptome analysis and signaling pathway analysis of circCDK13 overexpression in liver cancer. (A) Transcriptome analysis of liver cancer cells overexpressing circCDK13 induced by transfection with circCDK13 overexpression plasmid. Gene expression profiles were determined by microarray analysis (left panel), and the numbers of upregulated and downregulated genes are presented in a pie chart (right panel). (B) Major signaling pathways with enrichment of differentially expressed genes in circCDK13-overexpressing cells. KEGG analysis was performed to analyze the main signaling pathways with differentially expressed gene enrichment.

human cancers $(10,14,19)$. Facing the critical situation of liver cancer prevention and treatment, the application of circRNA molecules closely associated with liver cancer progression may be a promising strategy for the early diagnosis and novel therapeutic reagent screening. Recent large-scale sequencing endeavors have identified a large number of circRNAs from various human tissues and cells (30-32), and a public circRNA database is also available (29), providing a valuable research foundation for our understanding of the function of circRNAs. More importantly, verification and functional characterization are urgently required to disclose the specific expression, function, regulation and underlying mechanisms of these novel players under different physiological and pathological contexts. circCDK13 (hsa_circ_0001699) from the CDK13 gene was detected by several sequencing analyses in the mammalian brain (31), CD19+ B cells (30), and several normal and malignant human cells, such as K562, Nhek and HepG2 cells (32). However, the expression of circCDK13 must be verified in a case study, and little is known about its function and underlying mechanisms of action. In the present study, the expression of circCDK13 in human liver cancer cells and tissues was first verified by RT-qPCR, which confirmed the prevalent existence of this circular molecular during liver cancer progression.

To investigate the function of circCDK13 in liver cancer, liver cancer cells overexpressing circCDK13 by lentiviral transfection were established. The overexpression of circCDK13 significantly repressed the proliferative, migratory and invasive capacities of the liver cancer cells, and also altered cell cycle progression, directly revealing the function of circCDK13 in regulating liver cancer development. The role of circCDK13 is similar to that of another newly identified circRNA, hsa_circ_0004018, which has also been shown to be suppressed in hepatocellular carcinoma tissues (24). Of note, the expression of hsa_circ_0001649 has also been shown to be significantly downregulated in hepatocellular carcinoma tissues and correlated with tumor size (22). Additionally, the circRNA microarray has been applied for the large-scale identification of hepatocellular carcinoma-related circular RNAs, and >200 differential circRNAs were identified 
A

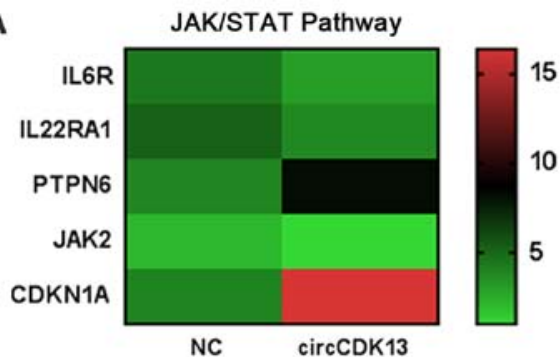

B
15

10

5
Huh7

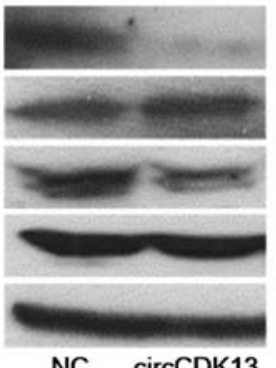

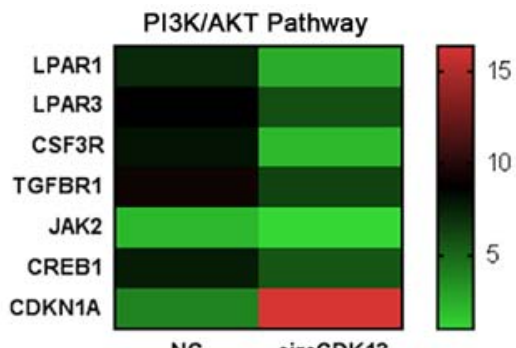

Sk-Hep-1

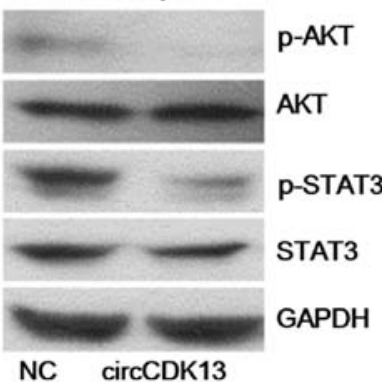

Figure 5. Regulation of JAK/STAT and PI3K/AKT by circCDKA13 in liver cancer cells. (A) Expression levels of major genes in the AK/STAT and PI3K/AKT signaling pathways were altered in response to circCDK13 overexpression induced by transfection with circCDK13 overexpression plasmid. The changes in gene expression were detected by transcriptome analysis. NC, negative control; circCDK13, circular CDK13 overexpression plasmid; IL6R, interleukin-6 receptor; IL22RA1, interleukin-22 receptor alpha 1; PTPN6, protein tyrosine phosphatase, non-receptor type 6; JAK, Janus kinase; CDKN1A, cyclin-dependent kinase inhibitor 1A; LPAR1, lysophosphatidic acid receptor 1; LPAR3, lysophosphatidic acid receptor 3; CSF3R, colony-stimulating factor 3 receptor; TGFBR1, transforming growth factor- $\beta$ type I receptor; CREB1, cAMP-responsive element-binding protein 1 . (B) Changes in the protein abundance of major JAK/STAT and PI3K/AKT signaling components induced by circCDK13 overexpression. The overexpression of circCDK13 downregulated the expression levels of phosphorylated AKT (p-AKT) and STAT3 (p-STAT3). The expression levels of total AKT, p-AKT, total STAT3 and p-STAT3 were determined by western blot analysis. GAPDH was used as an internal control.

A

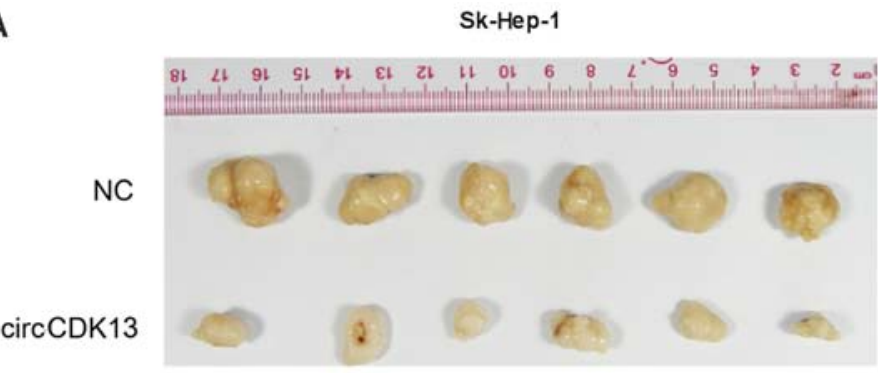

B

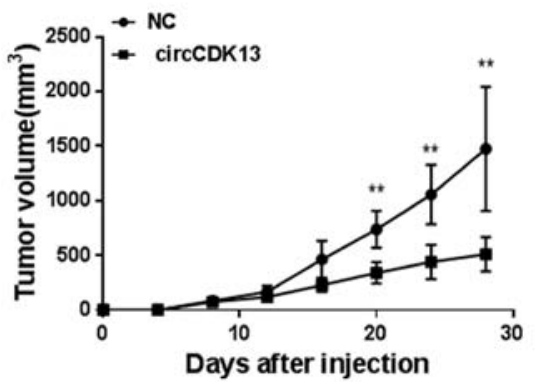

C

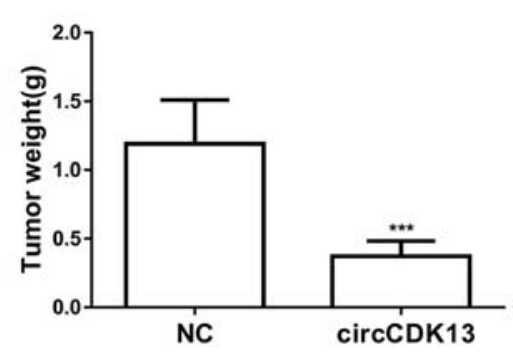

Figure 6. Suppression of tumorigenesis in mice by circCDK13 overexpression. (A) Tumors formed in nude mice transplanted with circCDK13-overexpressing liver cancer cells. The tumorigenicity assay was performed by the injection of Sk-Hep-1 cells into nude mice. (B) Volumes of tumors formed in nude mice injected with circCDK13-overexpressing Sk-Hep-1 cells. (C) Weights of tumors formed in nude mice injected with circCDK13-overexpressing Sk-Hep-1 cells. NC, negative control; circCDK13: circular CDK13 overexpression plasmid-transfected cells. ${ }^{* *} \mathrm{P}<0.01$, circCDK13 vs. NC; ${ }^{* * *} \mathrm{P}<0.001$, circCDK13 vs. NC.

in tissues from patients with hepatocellular carcinoma (25). The number of differentially expressed circRNAs associated with liver cancer progression has been rapidly increasing, and the functional characterization of these macromolecules in the context of liver cancer merits great efforts. The revelation of the cellular functions of a single circRNA in liver cancer is the first step, and accumulating knowledge concerning the large number of circRNAs during the pathology of liver cancer would 
provide important insight into the complex regulatory networks underlying the initiation and development of liver cancer. Our findings regarding the function of circCDK13 in cell behaviors, together with the markedly suppressed tumor size during tumorigenesis, as shown in Fig. 6, directly demonstrates that this novel circRNA acts as a potential suppressor of liver cancer.

The majority of recent studies examining circRNAs have focused on the expression patterns of circRNAs and cellular functions. The mechanisms of these circRNAs among the complex cellular signaling networks remain largely unexplored. In the present study, a microarray analysis was performed to explore the signaling pathways mediating the regulatory role of circCDK13. Many key components of the JAK/STAT and PI3K/AKT pathways were found to be differentially expressed and regulated by circCDK13 in liver cancer cells. The JAK/STAT signaling pathway has been established as very critical regulatory machinery for cytokine-dependent gene expression and cellular development and survival (43), and it is closely associated with many types of cancer (44). PI3K/AKT signaling, which controls cell growth, survival, cell cycle progression and other cellular functions, is also frequently altered in human cancers and is associated with the development of resistance to chemotherapy (45). The alteration of these signaling pathways by circCDK13 overexpression herein suggested that the cancer-inhibiting roles of circCDK13 may be mediated by these well-known cellular pathways. From the results of cell transcriptome sequencing, it was demonstrated that circCDK13 upregulates the JAK/STAT signaling pathway upstream suppressor genes (PTPN6). According to the mechanisms of sponging, the miR-135b-5p binding site is in circCDK13. A previous study reported that LZTS1 expression was inhibited by miR-135b-5p (46) and it suppressed HCC cell proliferation by inhibiting the activation of the PI3K/AKT pathway (47). Hence, circCDK13 may upregulate the relevant gene expression of the signaling pathway through sponge miRNAs to inhibit these two signaling pathways. In addition, a large number of genes involved in other cellular signaling pathways were also differentially expressed by the overexpression of circCDK13, inferring that this circRNA molecule could carry out its tumor suppressor role by modulating various signaling cascades in human cells. The large-scale transcriptome analysis of gene expression profiles regulated by a circRNA in this study also provides valuable clues for the investigations of other circRNAs associated with liver cancer.

It should also be noted that the direct targets of circCDK13 in liver cancer cells were not characterized in the present study. As reported, circRNAs may carry out their biological roles as sponges (11), and the future identification of target miRNAs would greatly enhance our understanding of their tumor suppressor functions. Furthermore, the great potential of circCDK13 to regulate cell proliferation and migration may also exist in other developmental processes and diseases, considering the ubiquitous expression of circCDK13 in various human tissues and cell lines (29). The study of circCDK13 in distinct physiological and pathological processes associated with cell proliferation and migration would broaden our knowledge of the functions of circRNAs.

In conclusion, we reported herein the expression of a novel circRNA, circCDK13, in liver cancer tissues and cell lines. The overexpression of circCDK13 suppresses liver cancer cell proliferation, migration, invasion and tumorigenesis, possibly mediated via the JAK/STAT and PI3K/AKT pathways. Our results characterize circCDK13 as a suppressive factor of liver cancer, and thus it may be explored as a biomarker for liver cancer diagnosis and treatment.

\section{Acknowledgements}

Not applicable.

\section{Funding}

This study was supported by the National Natural Science Foundation of China (grant nos. 31600710 and 81172193).

\section{Availability of data and materials}

The analyzed datasets generated during the study are available from the corresponding author on reasonable request.

\section{Authors' contributions}

QL and YBL design the research and draft the manuscript. JWC and CRZ conducted the experiments. JC and XL performed the data analysis. MSH critically reviewed and revised the manuscript and approved the final version to be published. All authors have read and approved the final manuscript.

\section{Ethics approval and consent to participate}

The liver cancer tissues used in this study were collected from patients with hepatocellular carcinoma after obtaining written informed consent signed by each patient. The sample collection processes and following analysis were approved by the Ethics Committee of the Third Affiliated Hospital of Sun Yat-sen University prior to the surgery. The mouse experiments in this study was performed under the Affidavit of the Approval of Animal Ethical and Welfare of the Laboratory Animal Center of the Third Affiliated Hospital of Sun Yat-sen University.

\section{Consent for publication}

Not applicable.

\section{Competing interests}

The authors declare that they have no competing interests.

\section{References}

1. Perz JF, Armstrong GL, Farrington LA, Hutin YJ and Bell BP: The contributions of hepatitis $B$ virus and hepatitis $C$ virus infections to cirrhosis and primary liver cancer worldwide. J Hepatol 45: 529-538, 2006.

2. Siegel RL, Miller KD and Jemal A: Cancer statistics, 2015. CA Cancer J Clin 65: 5-29, 2015.

3. Clark T, Maximin S, Meier J, Pokharel S and Bhargava P: Hepatocellular carcinoma: Review of epidemiology, screening, imaging diagnosis, response assessment, and treatment. Curr Probl Diagn Radiol 44: 479-486, 2015.

4. Hsueh CT, Liu D and Wang H: Novel biomarkers for diagnosis, prognosis, targeted therapy and clinical trials. Biomark Res 1: 1, 2013. 
5. Xu JB, Qi FZ, Xu G, Chen GF, Qin LX and Zhang JH: Value of alpha-fetoprotein and clinical characteristics in patients with liver neoplasm. Neoplasma 61: 218-224, 2014.

6. Prieto De Paula JM, Mayor Toranzo E, Gallardo Borge L and Franco Hidalgo S: Small-cell lung cancer and elevated CA 19.9 tumor marker levels. Arch Bronconeumol 48: 385-386, 2012 (In Spanish).

7. Zhang HX, Liu DD, Jin BJ, Wang YW, Liu Q, Duan RB, Zhao P and Ma MX: Changes of serum trace elements, AFP, CEA, SF, T3, T4 and IGF-II in different periods of rat liver cancer. Chin J Cancer Res 23: 301-305, 2011.

8. Zhang D, Yu M, Xu T and Xiong B: Predictive value of serum CEA, CA19-9 and CA125 in diagnosis of colorectal liver metastasis in Chinese population. Hepatogastroenterology 60: 1297-1301, 2013.

9. Benowitz S: Liver cancer biomarkers struggling to succeed. J Natl Cancer Inst 99: 590-591, 2007.

10. Dong Y, He D, Peng Z, Peng W, Shi W, Wang J, Li B, Zhang C and Duan C: Circular RNAs in cancer: An emerging key player. J Hematol Oncol 10: 2, 2017.

11. Hansen TB, Jensen TI, Clausen BH, Bramsen JB, Finsen B, Damgaard CK and Kjems J: Natural RNA circles function as efficient microRNA sponges. Nature 495: 384-388, 2013.

12. Sanger HL, Klotz G, Riesner D, Gross HJ and Kleinschmidt AK: Viroids are single-stranded covalently closed circular RNA molecules existing as highly base-paired rod-like structures. Proc Natl Acad Sci USA 73: 3852-3856, 1976.

13. Li J, Yang J, Zhou P, Le Y, Zhou C, Wang S, Xu D, Lin HK and Gong Z: Circular RNAs in cancer: Novel insights into origins, properties, functions and implications. Am J Cancer Res 5: 472-480, 2015

14. Wang Y, Mo Y, Gong Z, Yang X, Yang M, Zhang S, Xiong F, Xiang B, Zhou M, Liao Q, et al: Circular RNAs in human cancer. Mol Cancer 16: 25, 2017.

15. Jeck WR, Sorrentino JA, Wang K, Slevin MK, Burd CE, Liu J, Marzluff WF and Sharpless NE: Circular RNAs are abundant, conserved, and associated with ALU repeats. RNA 19: 141-157, 2013.

16. Salzman J, Gawad C, Wang PL, Lacayo N and Brown PO: Circular RNAs are the predominant transcript isoform from hundreds of human genes in diverse cell types. PLoS One 7: e30733, 2012

17. Li Z, Huang C, Bao C, Chen L, Lin M, Wang X, Zhong G, Yu B, $\mathrm{Hu}$ W, Dai L, et al: Exon-intron circular RNAs regulate transcription in the nucleus. Nat Struct Mol Biol 22: 256-264, 2015.

18. Granados-Riveron JT and Aquino-Jarquin G: The complexity of the translation ability of circRNAs. Biochim Biophys Acta 1859: $1245-1251,2016$

19. Greene J, Baird AM, Brady L, Lim M, Gray SG, McDermott R and Finn SP: Circular RNAs: Biogenesis, Function and Role in Human Diseases. Front Mol Biosci 4: 38, 2017.

20. Ren S, Xin Z, Xu Y, Xu J and Wang G: Construction and analysis of circular RNA molecular regulatory networks In liver cancer. Cell Cycle 16: 2204-2211, 2017.

21. Bai F, Yano Y, Fukumoto T, Takebe A, Tanaka M, Kuramitsu K Anggorowati N, Rinonce HT, Widasari DI, Saito M, et al: Quantification of pregenomic RNA and covalently closed circular DNA in hepatitis B virus-related hepatocellular carcinoma. Int J Hepatol 2013: 849290, 2013.

22. Qin M, Liu G, Huo X, Tao X, Sun X, Ge Z, Yang J, Fan J, Liu L and Qin W: Hsa circ 0001649: A circular RNA and potential novel biomarker for hepatocellular carcinoma. Cancer Biomark 16: 161-169, 2016.

23. Shang X,LiG,Liu H,LiT,Liu J,Zhao Q and Wang C: Comprehensive circular RNA profiling reveals that hsa_circ_0005075, a new circular RNA biomarker, is involved in hepatocellular carcinoma development. Medicine (Baltimore) 95: e3811, 2016.

24. Fu L, Yao T, Chen Q, Mo X, Hu Y and Guo J: Screening differential circular RNA expression profiles reveals hsa_circ 0004018 is associated with hepatocellular carcinoma. Oncotarget 8: 58405-58416, 2017.

25. Huang XY, Huang ZL, Xu YH, Zheng Q, Chen Z, Song W, Zhou J, Tang ZY and Huang XY: Comprehensive circular RNA profiling reveals the regulatory role of the circRNA-100338/miR-141-3p pathway in hepatitis B-related hepatocellular carcinoma. Sci Rep 7: 5428, 2017.

26. Greifenberg AK,HönigD,PilarovaK,DüsterR,BartholomeeusenK, Bösken CA, Anand K, Blazek D and Geyer M: Structural and functional analysis of the Cdk13/Cyclin K complex. Cell Rep 14: 320-331, 2016.
27. Even Y, Escande ML, Fayet $\mathrm{C}$ and Genevière AM: CDK13, a kinase involved in Pre-mRNA splicing, is a component of the perinucleolar compartment. PLoS One 11: e0149184, 2016.

28. Kim HE, Kim DG, Lee KJ, Son JG, Song MY, Park YM, Kim JJ, Cho SW, Chi SG, Cheong HS, et al: Frequent amplification of CENPF, GMNN and CDK13 genes in hepatocellular carcinomas. PLoS One 7: e43223, 2012.

29. Glažar P, Papavasileiou P and Rajewsky N: circBase: A database for circular RNAs. RNA 20: 1666-1670, 2014.

30. Memczak S, Jens M, Elefsinioti A, Torti F, Krueger J, Rybak A, Maier L, Mackowiak SD, Gregersen LH, Munschauer M, et al: Circular RNAs are a large class of animal RNAs with regulatory potency. Nature 495: 333-338, 2013.

31. Rybak-Wolf A, Stottmeister C, Glažar P, Jens M, Pino N, Giusti S, Hanan M, Behm M, Bartok O, Ashwal-Fluss R, et al: Circular RNAs in the mammalian brain are highly abundant, conserved, and dynamically expressed. Mol Cell 58: 870-885, 2015.

32. Salzman J, Chen RE, Olsen MN, Wang PL and Brown PO: Cell-type specific features of circular RNA expression. PLoS Genet 9: e1003777, 2013.

33. Thomas M: Molecular targeted therapy for hepatocellular carcinoma. J Gastroenterol 44 (Suppl 19): 136-141, 2009.

34. Tang H, Li RP, Liang P, Zhou YL and Wang GW: miR-125a inhibits the migration and invasion of liver cancer cells via suppression of the PI3K/AKT/mTOR signaling pathway. Oncol Lett 10: 681-686, 2015.

35. Wilson GS, Tian A, Hebbard L, Duan W, George J, Li X and Qiao L: Tumoricidal effects of the JAK inhibitor Ruxolitinib (INC424) on hepatocellular carcinoma in vitro. Cancer Lett 341: 224-230, 2013.

36. Sun ZJ, Chen G, Hu X, Zhang W, Liu Y, Zhu LX, Zhou Q and Zhao YF: Activation of PI3K/Akt/IKK- $\alpha /$ NF-kappaB signaling pathway is required for the apoptosis-evasion in human salivary adenoid cystic carcinoma: Its inhibition by quercetin. Apoptosis 15 : 850-863, 2010.

37. Booz GW, Day JN and Baker KM: Interplay between the cardiac renin angiotensin system and JAK-STAT signaling: Role in cardiac hypertrophy, ischemia/reperfusion dysfunction, and heart failure. J Mol Cell Cardiol 34: 1443-1453, 2002.

38. Levine DA, Bogomolniy F, Yee CJ, Lash A, Barakat RR, Borgen PI and Boyd J: Frequent mutation of the PIK3CA gene in ovarian and breast cancers. Clin Cancer Res 11: 2875-2878, 2005.

39. Or YY, Hui AB, Tam KY,Huang DP and Lo KW: Characterization of chromosome $3 \mathrm{q}$ and $12 \mathrm{q}$ amplicons in nasopharyngeal carcinoma cell lines. Int J Oncol 26: 49-56, 2005.

40. Xiong H, Zhang ZG, Tian XQ, Sun DF, Liang QC, Zhang YJ, Lu R, Chen YX and Fang JY: Inhibition of JAK1, 2/STAT3 signaling induces apoptosis, cell cycle arrest, and reduces tumor cell invasion in colorectal cancer cells. Neoplasia 10: 287-297, 2008.

41. Li F, Zhang L, Li W, Deng J, Zheng J, An M, Lu J and Zhou Y: Circular RNA ITCH has inhibitory effect on ESCC by suppressing the Wnt/ß-catenin pathway. Oncotarget 6: 6001-6013, 2015.

42. Simile MM, Latte G, Demartis MI, Brozzetti S, Calvisi DF, Porcu A, Feo CF, Seddaiu MA, Daino L, Berasain C, et al: Post-translational deregulation of YAP1 is genetically controlled in rat liver cancer and determines the fate and stem-like behavior of the human disease. Oncotarget 7: 49194-49216, 2016.

43. O'Shea JJ, Gadina M and Schreiber RD: Cytokine signaling in 2002: New surprises in the Jak/Stat pathway. Cell 109 (Suppl 1): S121-S131, 2002

44. Arumuggam N, Bhowmick NA and Rupasinghe HP: A Review: Phytochemicals targeting JAK/STAT signaling and IDO expression in cancer. Phytother Res 29: 805-817, 2015.

45. Fresno Vara JA, Casado E, de Castro J, Cejas P, Belda-Iniesta C and González-Barón M: PI3K/Akt signalling pathway and cancer. Cancer Treat Rev 30: 193-204, 2004.

46. Lin CW, Chang YL, Chang YC, Lin JC, Chen CC, Pan SH, Wu CT, Chen HY, Yang SC, Hong TM, et al: MicroRNA-135b promotes lung cancer metastasis by regulating multiple targets in the Hippo pathway and LZTS1. Nat Commun 4: 1877, 2013.

47. He Y and Liu X: The tumor-suppressor gene LZTS1 suppresses hepatocellular carcinoma proliferation by impairing PI3K/Akt pathway. Biomed Pharmacother 76: 141-146, 2015. 